\title{
STATUS HARA FOSFOR DAN KALIUM DI LAHAN SAWAH DI KECAMATAN TANJUNG MORAWA KABUPATEN DELI SERDANG
}

\section{Status of Phosphorus and Potassium Nutrients in Rice Field Area in Tanjung Morawa District of Deli Serdang Regency}

\author{
Riza Agoesdy ${ }^{*}$, Hamdiah Hanum ${ }^{2}$ dan Abdul Rauf ${ }^{2}$, Fitra Syawal Harahap ${ }^{3}$ \\ ${ }^{1}$ Program Magister Agroteknologi Faculty of Agriculture, University of Sumatera Utara, ${ }^{2}$ Progam Studi \\ Agroteknologi Faculty of Agriculture, University of Sumatera Utara, ${ }^{3}$ Progam Studi Agroteknologi \\ Sekolah Tinggi Ilmu Pertanian (STIPER) Yayasan Universitas Labuhan Batu \\ *Penulis koresondensi: riza.agoesdy@yahoo.co.id
}

\begin{abstract}
This research was conducted in Tanjung Morawa Subdistrict of Deli Serdang Regency in May 2017 until August 2017. This research was a qualitative descriptive phenomenological research with land survey supported by qualitative laboratory analysis. Soil sampling was done at the survey area sequentially based on the location where the soil characteristics were different from the purposive random sampling method, so the result of soil analysis obtained was expected to reflect the actual value. The soil sampling was taken at the top layer at the top soil depth of $0-20 \mathrm{~cm}, 60 \mathrm{~cm}$ and recording point coordinates by using GPS (global Positioning System). Soil chemical properties analyzed were $\mathrm{P}_{2} \mathrm{O}_{5} \mathrm{HCl} 25 \%\left(\mathrm{mg} 100 \mathrm{~g}^{-1}\right) ; \mathrm{K}_{2} \mathrm{O} \mathrm{HCl} \mathrm{25 \%}\left(\mathrm{mg} 100 \mathrm{~g}^{-1}\right)$, and the status of $\mathrm{P}$ and $\mathrm{K}$ of rice field of Tanjung Morawa District., Rice field with medium P status was T Morawa B Village (20.20 $\left.\mathrm{mg} 100 \mathrm{~g} \mathrm{~g}^{-1}\right)$, and that with low P status was Pardamean Village (6.34 $\left.\mathrm{mg} 100 \mathrm{~g}^{-1}\right)$, Wonosari

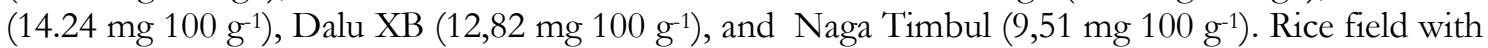
high K status was Pardaeman Village (69,07 mg $\left.100 \mathrm{~g}^{-1}\right)$, and Dalu XB (69,07 mg $\left.100 \mathrm{~g}^{-1}\right)$. Rice filed with medium $\mathrm{K}$ status was Wonosari Village $\left(27.43 \mathrm{mg} 100 \mathrm{~g}^{-1}\right)$. Rice field with low $\mathrm{K}$ status

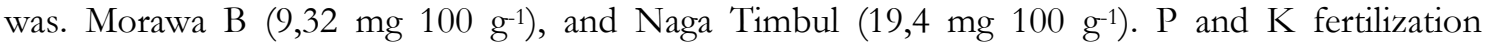
recommendation need to be corrected especially for soils having high $\mathrm{P}$ nutrient for efficient use of $\mathrm{P}$ fertilizer and eficcient farming. Rice straw needs to be returned to paddy field to increase $\mathrm{K}_{2} \mathrm{O}$ level of soil, in addition to $\mathrm{K}$ fertilizer $\mathrm{K}$.
\end{abstract}

Keywords: nutrient status, paddy soils, phosphorus, potassium

\section{Pendahuluan}

Pemupukan fosfor (P) dan kalium (K) memegang peranan penting dalam meningkatkan produksi pertanian disamping pupuk nitrogen. Umumnya penggunaan pupuk tersebut belum rasional dan berimbang karena belum didasarkan pada potensi atau status hara tanah dan kebutuhan tanaman. Pada lahan sawah intensifikasi pemakaian pupuk $P$ cenderung berlebih, sehingga banyak penelitian yang menunjukkan bahwa pemberian pupuk $\mathrm{P}$ pada tanaman tidak diikuti dengan peningkatan hasil serta etisiensinya sangat rendah, sementara harga pupuk tersebut cukup mahal. Dari hasil analisis, jumlah $P$ yang terangkut pada saat panen cukup keeil dan fosfat yang diserap tanaman padi pada laban irigasi 15 - 20\% dan pada lahan kering hanya $10-15 \%$ dari takaran pupuk yang diberikan, sementara sisanya tinggal didalam tanah sebagai residu dalam bentuk senyawa $\mathrm{P}$ (Adiningsih, 2004). Terdapat lima parameter tanah yang digunakan dalam penelitian ini untuk menilai status kesuburan tanah (Adiningsih, 2004). 


\section{Jurnal Tanah dan Sumberdaya Lahan Vol 6 No 2 : 1387-1390, 2019 e-ISSN:2549-9793, doi: 10.21776/ub.jts1.2019.006.2.19}

Menurut Dobermann dan Fairhurst (2000), setiap ton gabah membutuhkan sekitar $2.6 \mathrm{~kg} \mathrm{P}$ $\mathrm{ha}^{-1}$. Selain itu, pupuk $\mathrm{P}$ bila terus-menerus diberikan dengan dosis berlebihan menyebabkan peneemaran lingkungan dan ketidak seimbangan hara. Tanggap tanaman terhadap pemupukan kalium juga berbeda, tergantung status kalium di dalam tanah dan faktor-faktor yang berpengaruh terhadap proses penyerapan kalium oleh padi sawah.

Banyak lahan sawah yang kahat $\mathrm{K}$ terutama pada tanah Aerie Endoaquept, dimana kandungan $\mathrm{K}$ dapat ditukar kurang dari $0.1 \mathrm{me} 100 \mathrm{~g}^{-1}$ (Wihardjaka et al., 2002). Sofyan et al. (2004) menyatakan lahan sawah berstatus $\mathrm{K}$ tinggi diakibatkan oleh pemupukan $\mathrm{K}$ yang dilakukan secara terus-menerus. Pemupukan K yang dilakukan secara terus-menerus menyebabkan ketidakseimbangan hara tanah yang disinyalir mengakibatkan terjadinya leveling off padi sawah. Untuk itu perlu dilakukan evaluasi kembali terhadap status hara $\mathrm{K}$ tanah sawah di Pulau Jawa guna meningkatkan efisiensi penggunaan pupuk dan menjaga hasil padi sawah tetap tinggi.

Etisiensi penggunaan pupuk dapat ditingkatkan dengan menyusun rekomendasi spesitik lokasi yang didasarkan pada rangkaian uji tanah untuk suatu sistem hara-tanahtanaman. Pada dasarnya tahapan kegiatan uji tanah meliputi : (I) pengambilan eontoh tanah yang mewakili lokasi, (2) analisis kimia tanah di laboratorium dengan metode yang tepat dan teruji, (3) interpretasi hasil analisis, dan (4) rekomendasi pemupukan (Adiningsih, 2004). Penetapan status hara merupakan rangkaian kegiatan dari tahap pertama sampai ketiga, dimana asilnya dituangkan dalam Tabel status hara tanah Badan Penelitian dan Pengembangan Pertanian Kementan (2012).

Ketersediaan P pada tanah sawah/tergenang lebih tinggi dibandingkan pada kondisi aerob/kering, ini disebabkan karena pada kondisi anaerob terjadi pelarutan Fe (besi feri menjadi fero) sehingga P terlepas. Survei kesuburan tanah sawah yang dilakukan di 21 provinsi menunjukkan bahwa dari 7,5 juta ha lahan sawah intensifikasi, sekitar 3 juta ha mempunyai status hara $\mathrm{P}$ tinggi (dengan konsentrasi $\mathrm{P}_{2} \mathrm{O}_{5}$ terekstrak $\mathrm{HCl} 25$ persen > $40 \mathrm{mg} 100 \mathrm{~g}^{-1}$ ); 3,24 juta ha mempunyai status hara $\mathrm{P}$ sedang (konsentrasi $\mathrm{P}_{2} \mathrm{O}_{5}$ antara 20- 40 mg $100 \mathrm{~g}^{-1}$ ); dan hanya 1,3 juta ha mempunyai status hara $\mathrm{P}$ rendah $\left(\mathrm{P}_{2} \mathrm{O}_{5}\right.$ terekstrak $\mathrm{HCl} 25$ persen $<20 \mathrm{mg} 100 \mathrm{~g}^{-1}$ ) (Sofyan et al., 2000). Status hara $\mathrm{P}$ tanah yang tinggi diakibatkan oleh akumulasi pemupukan $\mathrm{P}$ pada periode sebelumnya.

Kadar K di dalam tanah dapat dipengaruhi oleh bahan induk tanah, pada tanah sawah umumnya kandungan $\mathrm{K}$ berkisar sedang-tinggi. $\mathrm{K}$ dalam tanah mempunyai sifat yang mudah bergerak (mobile) sehingga mudah hilang melalui proses pencucian atau terbawaarus pergerakan air. Sehingga efisiensi pupuk $\mathrm{K}$ biasanya rendah. Hasil survei kesuburan tanah sawah menunjukkan bahwa sebaran status $\mathrm{K}$ tanah cenderung sama dengan status P tanah. Dari luas total lahan sawah 7,5 juta ha, sekitar 3,8 juta ha (51 persen) lahan sawah intensifikasi mempunyai status hara $\mathrm{K}$ tinggi $\left(\mathrm{K}_{2} \mathrm{O}\right.$ terekstrak $\mathrm{HCl} 25$ persen $>20 \mathrm{mg}$ $\left.100 \mathrm{~g}^{-1}\right) ; 2,8$ juta ha (37 persen) mempunyai status $\mathrm{K}$ sedang (konsentrasi $\mathrm{K}_{2} \mathrm{O} \quad 10-20 \mathrm{mg}$ $\left.100 \mathrm{~g}^{-1}\right)$, dan hanya 0,88 juta ha (12 persen) mempunyai status $\mathrm{K}$ rendah (konsentrasi $\mathrm{K}_{2} \mathrm{O}<10 \mathrm{~m} 100 \mathrm{~g}^{-1}$ ) (Sofyan et al., 2000). Menurunnya kesuburan tanah dapat menjadi faktor utama yang mempengaruhi produktivitas tanah, sehingga penambahan unsur hara dalam tanah melalui proses pemupukan sangat penting dilakukan agar diperoleh produksi pertanian yang menguntungkan. Penetapan selang status hara $\mathrm{P}$ dan $\mathrm{K}$ berdasarkan ekstrak $\mathrm{HCl} 25 \%$ tersebut didasarkan pada hasil penelitian Moersidi et al. (1991) dan Rochayati et al. (1991) di Jawa, serta hasil penelitian Soepartini et al., (1994) di Lombok, dimana ekstrak $\mathrm{HCl} 25 \%$ paling tioggi korelasinya untuk padi sawah dibandingkan beberapa ekstraktan yang lain.

Menurut BPS (2016), Kecamatan Tanjung Morawa memiliki luas panen 5322,94 ha dengan rata-rata produksi $873,30 \mathrm{kw} \mathrm{ha}^{-1}$ atau $8,73 \mathrm{t} \mathrm{ha}^{-1}$ pada tahun 2015. Kecamatan Tanjung Morawa diharapkan kedepannya menjadi kecamatan yang memiliki tingkat produktivitas padi sawah tertinggi dibandingkan dengan kecamatan lainnya yang ada di Kabupaten Deli Serdang. Setelah dilakukan analisis awal pada lahan sawah di Kecamatan Tanjung Morawa, dimana lahan sawah tersebut merupakan lahan terdegradasi yang ditandai dengan kandungan bahan organik 


\section{Jurnal Tanah dan Sumberdaya Lahan Vol 6 No 2 : 1387-1390, 2019 \\ e-ISSN:2549-9793, doi: 10.21776/ub.jts1.2019.006.2.19}

yang sangat rendah $<1 \%$. Penelitian ini bertujuan untuk membagi kelas status hara $\mathrm{P}$ dan $\mathrm{K}$ tanah sawah di Kabupaten Deli Serdang menjadi tiga bagian yaitu rendah, sedang dan tinggi sehingga dapat digunakan sebagai arahan untuk rekomendasi pemupukan $\mathrm{P}$ dan K.

\section{Metode Penelitian}

Penelitian ini dilaksanakan di Kecamatan Tanjung Morawa Kabupaten Deli Serdang .Penelitian ini akan dilaksanakan dari bulan Mei 2017 sampai Agustus 2017. Penelitian ini merupakan penelitian deskriptif kualitatif fenomenologis dengan survai lahan dan didukung analisis laboratorium secara kualitatif. Pengambilan sampel tanah dilakukan pada areal survei secara sekuen berdasarkan tempat diperkirakan sifat tanahnya berbeda dengan metode purposive random sampling, maka hasil analisis tanah yang diperoleh diharapkan dapat mencerminkan nilai sebenarnya Pengambilan sampel tanah diambil pada lapisan atas pada kedalaman top soil $0-20 \mathrm{~cm}, 30-60$ $\mathrm{cm}$ dan dilakukan perekaman titik koordinat dengan menggunakan GPS (global Positioning System). Sedangkan informasi pengelolaan tanah diperoleh dengan cara pengamatan langsung dilapangan dan wawancara dengan petani secara mendalam secara snow ball yang bertujuan untuk memperoleh informasi yang lengkap dari petani.

Sampel-sampel tanah yang telah diambil dilapangan, selanjutnya dianalisis di laboratorium PT. Socfin Indonesia. Sifat-sifat kimia tanah yang dianalisis $\mathrm{P}_{2} \mathrm{O}_{5} \mathrm{HCl} 25 \%(\mathrm{mg}$ $100 \mathrm{~g}^{-1}$ ) ; $\mathrm{K}_{2} \mathrm{O} \mathrm{HCl} \mathrm{25 \%}$ (mg $100 \mathrm{~g}^{-1}$ ) (BP2KP, 2009). Untuk mengetahui sifat- sifat kimia tanah dengan kriteria tertentu yang telah ditentukan. Berdasarkan Petunjuk Teknis Evaluasi Kesuburan Tanah (BP2KP,2012) yang disajikan pada Tabel 1.

Tabel 1. Kriteria penilaian status hara.

\begin{tabular}{|c|c|c|c|c|c|}
\hline Sifat Tanah & $\begin{array}{l}\text { Sangat } \\
\text { Rendah }\end{array}$ & Rendah & Sedang & Tinggi & $\begin{array}{l}\text { Sangat } \\
\text { Tinggi }\end{array}$ \\
\hline $\mathrm{P}_{2} \mathrm{O}_{5} \mathrm{HCl} 25 \%\left(\mathrm{mg} 100 \mathrm{~g}^{-1}\right)$ & $<10$ & $10-20$ & $21-40$ & $41-60$ & $>60$ \\
\hline $\mathrm{K}_{2} \mathrm{O} \mathrm{HCl} 25 \%\left(\mathrm{mg} 100 \mathrm{~g}^{-1}\right)$ & $<10$ & $10-20$ & $21-40$ & $41-60$ & $>60$ \\
\hline
\end{tabular}

Sumber : Badan Penelitian dan Pengembangan Pertanian Kementan (2012)

\section{Hasil dan Pembahasan}

Pengambilan contoh hanya dilakukan pada lima Desa Kecamatan Tanjung Morawa di Kabupaten Desa Serdang yang diutamakan pada lahan sawah irigasi. Satus hara P kisaran kadar hara Posfat di lima Desa di Kecamatan Tanjung Morawa. Dari hasil analisis kadar hara P tanah, hampir semua kecamatan yang dianalisis contoh tanahnya memiliki kriteria status hara P rendah, sedang dan tinggi. Kadar hara P bervariasi antara 9,51 - 20,20 mg $100 \mathrm{~g}^{-1}$ (Tabel 2). Satus Hara K Kisaran kadar hara Kalium di lima Desa di Kecamatan Tanjung Morawa. Dari hasil analisis kadar hara $\mathrm{K}$ tanah, hampir semua kecamatan yang dianalisis contoh tanahnya memiliki kriteria status hara $\mathrm{K}$ rendah, sedang dan tinggi. Kadar hara $\mathrm{K}$ bervariasi antara 9,32 - 69,07 $\mathrm{mg} 100 \mathrm{~g}^{-1}$. (Tabel 2). Dominasi status hara P tinggi pada lahan sawah ini disebabkan antara lain pemupukan yang intensif pada lahan sawah irigasi teknis dengan intensitas tanam dua atau tiga kali setahun sementara tidak semua pupuk $P$ yang diberikan dapat diserap tanaman.

Tabel 2. Analisis status hara di Kecamatan Tanjung Morawa.

\begin{tabular}{|c|c|c|}
\hline \multirow[t]{3}{*}{ Desa } & \multicolumn{2}{|c|}{ Analisis Tanah } \\
\hline & $\mathbf{P}_{2} \mathbf{O}_{5}$ & $\mathrm{~K}_{2} \mathrm{O}$ \\
\hline & $\begin{array}{l}\mathrm{HCl} 25 \% \\
\left(\mathrm{mg} 100 \mathrm{~g}^{-1}\right)\end{array}$ & $\begin{array}{c}\mathrm{HCl} \mathrm{25 \%} \\
\left(\mathrm{mg} 100 \mathrm{~g}^{-1}\right)\end{array}$ \\
\hline Pardamean & $6.34(\mathrm{R})$ & $69.07(\mathrm{~T})$ \\
\hline Wonosari & $14.24(\mathrm{R})$ & $27.43(\mathrm{~S})$ \\
\hline Dalu X B & $12.82(\mathrm{R})$ & $59.02(\mathrm{~T})$ \\
\hline T.Morawa B & $20.20(\mathrm{~S})$ & $9.32(\mathrm{R})$ \\
\hline Naga Timbul & $9.51(\mathrm{R})$ & $19.4(\mathrm{R})$ \\
\hline
\end{tabular}

Keterangan: AM: Agak Masam, SR: Sangat Rendah, R: Rendah, T: Tinggi, ST: Sangat Tinggi 


\section{Jurnal Tanah dan Sumberdaya Lahan Vol 6 No 2 : 1387-1390, 2019 e-ISSN:2549-9793, doi: 10.21776/ub.jts1.2019.006.2.19}

Diduga sebagian besar pupuk P terakumulasi di dalam tanah karena ftksasi $P$ oleh aluminium dan besi menjadi senyawa Al-P dan Fe-P (Taher, 1993). Menurut Abdurrahman, et al. (2002), pupuk P yang diberikan pada tanah sawah, hanya sebesar 20 - 30 persen saja yang diserap tanaman padi. Status hara K lahan sawah di Kecamatan Tanjung Morawa Kabupaten Deli Serdang yang pada umumnya rendah diduga selain berbaban induk batu pasir dan juga disebabkan kebiasaan petani yang tidak ataupun memberikan pupuk $\mathrm{K}$ dalam jumlab yang sedikit pada setiap musim tanam. Selain itu, kebanyakan petani tidak mengembalikan jerami atau sisa-sisa tanaman padi ke dalam tanab melainkan membakarnya Oleh karena itu, pengembalian jerami ke dalam tanah dapat memperlambat pemiskinan $\mathrm{K}$ dan $\mathrm{Si}$ tanah. Pengembaliian jerami padi ke dalam lahan sawah berpotensi sebagai pupuk $\mathrm{K}$, baik diberikan dalam segar, dikomposkan maupun dibakar. Selain dapat menggantikan pupuk K pada takaran tertentu, jerami juga berberan penting dalam memperbaiki produktivitas tanah sawah, meningkatkan efisiensi pupuk dan menjamin kemantapan produksi (Wihardjaka et al., 2002).

\section{Kesimpulan}

Lahan sawah berstatus $\mathrm{P}$ sedang Desa T. Morawa B (20.20 mg $\left.100 \mathrm{~g}^{-1}\right)$ dan berstatus P rendah Desa Pardamean (6,34 mg 100 $\left.\mathrm{g}^{-1}\right)$, Wonosari (14.24 mg 100 $\left.\mathrm{g}^{-1}\right)$, Dalu X B (12,82 mg 100g-1), Naga Timbul (9,51 mg $\left.100 \mathrm{~g}^{-1}\right)$. Lahan sawah berstatus $\mathrm{K}$ tinggi Desa Pardaeman (69,07 mg 100g-1), Dalu X B (69,07 mg $\left.100 \mathrm{~g}^{-1}\right)$, K sedang Desa Wonosari (27.43 $\left.\mathrm{mg} 100 \mathrm{~g}^{-1}\right)$, dan rendah T. Morawa B (9,32 $\mathrm{mg}$ $\left.100 \mathrm{~g}^{-1}\right)$, Naga Timbul $\left(19,4 \mathrm{mg} \quad 100 \mathrm{~g}^{-1}\right)$. Rekomendasi pemupukan $\mathrm{P}$ dan K perlu dikoreksi terutama pada laban-lahan yang berstatus hara $\mathrm{P}$ tinggi untuk efisiensi penggunaan pupuk $\mathrm{P}$ dan eflsiensi usaha tani. Jerami padi perlu dikembalikan ke laban sawah untuk meningkatkan kadar $\mathrm{K}_{2} \mathrm{O}$ tanah, disamping pemberian pupuk $\mathrm{K}$.

\section{Daftar Pustaka}

Abdulrachman, S., Witt, C. dan Buresh, R. 2002. Pengembangan Metode Pengelolaan Unsur
Hara Spesifik Lokasi Lokakarya Pengelolaan Hara P dan K Sawah. Balai Penelitian Tanaman Padi Sukamandi.

Adiningsih, S. 2004. Dinamika hara dalam tanah dan mekanisme serapan hara dalam kaitannya dengan sifat-sifat tanab dan aplikasi pupuk. LPI dan APPI, Jakarta.

Badan Penelitian dan Pengembangan Pertanian Kementerian Pertanian (BP2KP). 2012. Petunjuk Teknis Analisis Kimia Tanah, Tanaman, Air dan Pupuk. Edisi 2. Bogor. 204 hal.

Dobbermann, A. and Fairhurst, T. 2000. Nutrient disorders and nutrient management. IRRl and Potash \& PPU PPIC. Manila, Philipina.

Moersidi, S., Prawirasumantri, J., Hartatik, W., Pramudia, A. dan Sudjadi, M. 1991. Evaluasi kedua keperluan fosfat pada lahan sawab intensifikasi di Jawa. Pros. Lokakarya Nasional Efisiensi Penggunaan Pupuk V. Pusat Penelitian Tanah dan Agroklimat, Bogor.

Rochayati, S., Mulyadi dan Adiningsih, J.S. 1991. Penelitian efisiensi penggunaan pupuk di laban sawab. Pros. Lokakarya Nas. Efisiensi Penggunaan Pupuk V. Pusat Penelitian Tanah dan Agroklimat, Bogor.

Soepartini, M., Nurjaya, Kasno, A., Arjakusuma, S., Moersidi, S. dan Adiningsih, J.S. 1994. Status hara $\mathrm{P}$ dan $\mathrm{K}$ serta sifat- sifat tanab sebagai penduga kebutuhan pupuk padi sawah di P. Lombok. Pemberitaan Peneletian. Tanah dan Pupuk 12: 23 - 25.

Sofyan, A, Nurjaya, Kasno, A. 2004. Status hara tanah sawah untuk rekomendasi. Hlm. 83 dalam Tanah Sawah dan Teknologi Pengelolaannya. Bogor: Pusat Penelitian Tanah dan Agroklimat.

Sofyan, A., Sediyarso, M., Nurjaya, dan Suryono, J. 2000. Laporan akhir penelitian statushara P dan $\mathrm{K}$ lahan sawah sebagai dasar penggunaan pupuk yang efisien pada tanaman pangan. Bagian Proyek Sumberdaya Lahan dan Agroklimat. Puslittanak, Bogor.

Taher, A. 1993. Pemanfaatan timbunan fosfat di laban sawah. Pros. Simposium Penel. Tan. Pangan III. Kinetja Penel. Tan. Pangan Buku III. Pusat Penel. Tan. Pangan, Bogor

Wihardjaka, A., Idris, K., Rachim, A. dan Partohardjono, S. 2002. Pengelolaan jerami dan pupuk kalium pada tanaman padi di laban sawah tadah hujan kahat K. Jurnal Penelitian Pertanian Tanaman Pangan 21 (1): 15-22. 